\title{
Immersion temperature effects on light-duty gasoline vehicles' fuel consumption under world-wide harmonized light-duty test cycle (WLTC)
}

\author{
Guangyao Wang ${ }^{*}$, Hongyu Qin, Deyu Meng, and Ziye Wang \\ China Automotive Technology and Research Center Co., Ltd., Tianjin 300300, China
}

Keywords: immersion temperatures, fuel consumption, light-duty gasoline vhicles, world-wide harmonized light-duty test cycle.

\begin{abstract}
Basing on the experimental study of fuel consumbtion in World-wide Harmonized Light-duty Test Cycle (WLTC ), this paper conducted the effects of using different immersion temperature on the fuel consumption of a light-duty gasoline vehicle. The study mainly studied the first phase of WLTC with three gaseous pollutant emissions: carbon dioxide, carbon monoxide and unburned hydrocarbon $\left(\mathrm{CO}_{2}, \mathrm{CO}\right.$ and $\mathrm{HC}$ )which is measured to caculate the fuel consumption of Light-duty Gasoline Vehicles. It appears that with the increase of time the working condition of the vehicle tends to be stable resulting in the similar emission of the gaseous pollutant in the different test. Which means the immersion temperature mainly effects gaseous pollutant emissions in low-speed phase in WLTC. Besides, the cold start of engine had generated a large quantity of carbon monoxide and unburned hydrocarbon, but it is different for the carbon dioxide which was generated continuously in the first whole phase. The study also found that the use of a higher immersion temperatures $\left(26^{\circ} \mathrm{C}\right)$ is more favorable than a lower immersion temperatures $\left(23^{\circ} \mathrm{C}\right)$ in the typy of testing vehicle' $\mathrm{s}$ fuel consumption in the WLTC test cycle.
\end{abstract}

\section{Introduction}

In recent years, with the development of China's road traffic and the further promotion of the trend of automobile growth, the number of motor vehicles in China has reached 330 million by the end of March 2019, including 246 million vehicles. The total number and growth of motor vehicles rank first in the world. At the same time, with the gradual depletion of non-renewable fossil fuel resources such as oil, human long-term normal life is threatened. In order to ensure the sustainable development of the whole social economy, it is imperative to reduce automobile fuel consumption.

In the early 1980s, China began to formulate the fuel consumption standard for automobiles and it is July 2003 when $<<$ Measurement methods of fuel consumption for

\footnotetext{
${ }^{*}$ Corresponding author: wangguangyao@catarc.ac.cn
} 
light-duty vehicles $>>(\text { GB 19233-2003 })^{[1]}$ was formulated, and then in September 2004 the $<<$ Fuel consumption limits for passenger cars $>>$ (GB 19578-2004) ${ }^{[2]}$ was formulated, which is the first mandatory standard for controlling fuel consumption of automobiles in China. At present, according to the above two standards, the fuel consumption test of light-duty vehicles is carried out under NEDC (New European Driving Cycle), but the automobile industry has started to formulate the third stage fuel consumption limit standard, which will take WLTC (World Wide Harmonized Light-duty Test Cycle) as the test condition $^{[14,16]}$.

At present, there are few studies on the influencing factors of fuel consumption of ligh-dutyt vehicles under WLTC working condition in the certification process, in the meantime, there is a wide range of immersion temperature required by GB 18352.6-2016 $<<$ Limits and measurement methods for emissions from light-duty vehicles (Phase 6 in China) $\gg$ [3], P49, The temperature control target of the immersion zone is $23{ }^{\circ} \mathrm{C}$, and the allowable actual deviation is $\pm 3^{\circ} \mathrm{C}$. So this article takes a look into he influence of different immersion temperature on the fuel consumption of a light-duty vehicle.

\section{Test Equipment and parameters}

\subsection{Test vehicle and fuel parameters}

The vehicle to be tested is a light vehicle on sale in the market. Its emission capacity reaches the national six emission level. There is no other load except for the driver. The vehicle's fuel filling volume is $50 \%$. See Table 1 for vehicle and fuel related parameters.

Table 1. Vehicle to be tested and test fuel parameters.

\begin{tabular}{|l|l|}
\hline Parameters & Value \\
\hline Test Mass/kg & 1715.5 \\
\hline Transmission Form & CVT \\
\hline Driving Tier Pressure/kPa & 24000 \\
\hline Engine Displacement $/ \mathrm{L}$ & 1.987 \\
\hline Rates Power of Engine/kW & 131 \\
\hline Driving Form & Front Wheel Drive \\
\hline Fuel Type & Gasoline \\
\hline Engine Oil Supply Mode & Gasoline Direct-injection \\
\hline Gasoline Density At $15^{\circ} \mathrm{C}\left(\mathrm{kg} / \mathrm{m}^{3}\right)$ & 0.7549 \\
\hline Octane Number & 95.8 \\
\hline
\end{tabular}

\subsection{Test equipment}

The composition of the test system is shown in Figure 1, and the equipment model is shown in Table 2. The whole test system is divided into five parts: the vehicle to be tested, chassis dynamometer, constant volume sampler (CVS), exhaust analyzer and console. During the test, load the resistance on the chassis dynamometer according to the coast down that had been down the day before the official test, and then test the vehicle according to the WLTC working condition. After the whole test cycle, the vehicle exhaust emission test system analyzes the diluted sample gas in the sampling bag to get the amount of carbon dioxide $\left(\mathrm{CO}_{2}\right)$, carbon monoxide (CO) and total unburned hydrocarbon (THC) emitted by the vehicle, and then calculate the fuel consumption of light vehicles under the WLTC working condition measurement. 


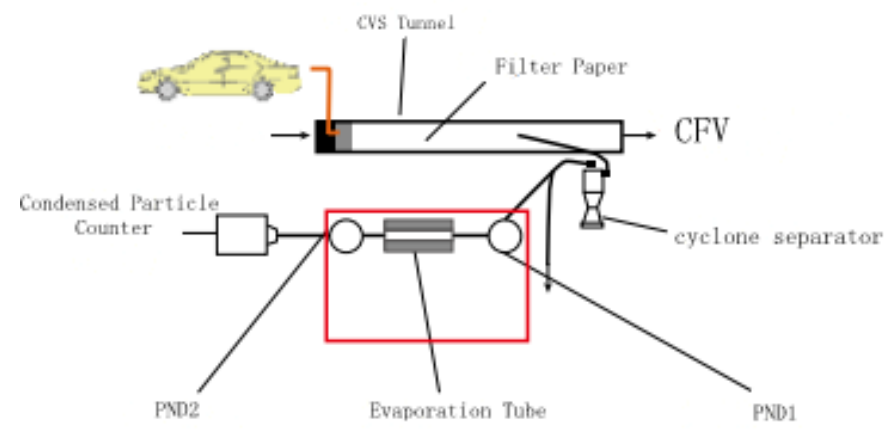

Fig. 1. Test system structure.

Table 2. Model of test equipment.

\begin{tabular}{|c|c|c|}
\hline Equipment & Production Plant & Model \\
\hline $\begin{array}{c}\text { Light-duty Vehicle exhaust emission } \\
\text { test system }\end{array}$ & Horiba, Japan & MEXA-7200H \\
\hline $\begin{array}{c}\text { AVL Four-wheel Chassis } \\
\text { Dynamometer }\end{array}$ & AVL, Austria & 48 WD \\
\hline Constant Volume Sampling System & Horiba, Japan & CVS-7400T \\
\hline
\end{tabular}

\subsection{Fuel consumption calculation}

The fuel consumption is calculated according to GB 19233-2003 $<<$ Measurement methods of fuel consumption for light-duty vehicles $>>$ for fuel consumption of light-duty vehicles. The $\mathrm{CO}_{2}, \mathrm{CO}$ and THC emissions of vehicles under WLTC condition are measured, and the fuel consumption is calculated by carbon balance method ${ }^{[1], P 5}$, and the fuel consumption formula is calculated (for vehicles equipped with gasoline engine).

$$
\mathrm{FC}=\frac{0.1154}{\mathrm{D}}\left[(0.866 \times \mathrm{HC})+(0.429 \times \mathrm{CO})+\left(0.273 \mathrm{CO}_{2}\right)\right]
$$

In formula: $\mathrm{FC}$ is the fuel consumption, $\mathrm{L} / 100 \mathrm{~km} ; \mathrm{HC}$ is the measured total hydrocarbon emission, $\mathrm{g} / \mathrm{km}$; $\mathrm{CO}$ is the measured $\mathrm{CO}$ emission, $\mathrm{g} / \mathrm{km} ; \mathrm{CO}_{2}$ is the measured $\mathrm{CO}_{2}$ emission, $\mathrm{g} / \mathrm{km}$; D is the density of the test fuel at $288 \mathrm{k}\left(15{ }^{\circ} \mathrm{C}\right), \mathrm{kg} / \mathrm{L}$.

\section{Test method and result analysis}

In this paper, the test vehicle was handled by the same pre-condiction method and soaked in two different immersion environments with the temperature of $23{ }^{\circ} \mathrm{C}$ and $26{ }^{\circ} \mathrm{C}$ for 24 hours. After the immersion, WLTC test condition will be used to test the fuel consumption. In order to reduce the error, the same driver will be used for each time of the pre-condiction and official test, and three tests will be carried out under each immersion temperature. The measured results of fuel consumption are mainly determined by $\mathrm{CO}_{2}, \mathrm{CO}$ and THC (for example, formula 1). Table 3 shows the partial exhaust gas emission and fuel consumption values of light-duty vehicles under WLTC working conditions measured with different immersion temperatures $\left(23^{\circ} \mathrm{C}\right.$ and $\left.26^{\circ} \mathrm{C}\right)$. 
Table 3. Vehicle exhaust pollutants and fuel consumption values under different soak temperatures in WLTC test cycle.

\begin{tabular}{|c|c|c|c|c|c|c|c|c|c|c|c|c|c|}
\hline \multirow{3}{*}{$\begin{array}{l}\text { Tempertur } \\
\mathrm{e}\end{array}$} & \multicolumn{12}{|c|}{ Exhaust Emission / mg } & \multirow{3}{*}{$\begin{array}{l}\text { Fuel } \\
\text { consumbtion/ } \\
\left(\mathrm{L} \cdot 100 \mathrm{~km}^{-1}\right)\end{array}$} \\
\hline & \multicolumn{3}{|c|}{ Phase 1(low speed) } & \multicolumn{3}{|c|}{$\begin{array}{l}\text { Phase2(middle } \\
\text { speed) }\end{array}$} & \multicolumn{3}{|c|}{ Phase3(high speed) } & \multicolumn{3}{|c|}{$\begin{array}{l}\text { Phase4(ex-high } \\
\text { speed) }\end{array}$} & \\
\hline & $\mathrm{CO}_{2}$ & $\mathrm{CO}$ & $\begin{array}{l}\text { TH } \\
\mathrm{C}\end{array}$ & $\mathrm{CO}_{2}$ & $\mathrm{CO}$ & THC & $\mathrm{CO}_{2}$ & $\mathrm{CO}$ & $\begin{array}{l}\text { TH } \\
\mathrm{C}\end{array}$ & $\mathrm{CO}_{2}$ & $\mathrm{CO}$ & $\mathrm{THC}$ & \\
\hline \multirow{3}{*}{$26^{\circ} \mathrm{C}$} & 584.87 & 2.62 & 0.19 & 692.70 & 0.19 & 0.01 & 906.10 & 0.41 & 0.01 & 1294.04 & 1.13 & 0.03 & 6.308 \\
\hline & 584.22 & 2.69 & 0.19 & 684.79 & 0.18 & 0.01 & 911.79 & 0.36 & 0.00 & 1294.63 & 1.11 & 0.03 & 6.318 \\
\hline & 579.70 & 2.68 & 0.19 & 683.79 & 0.17 & 0.00 & 896.26 & 0.35 & 0.00 & 1273.67 & 0.99 & 0.04 & 6.247 \\
\hline \multirow[t]{3}{*}{$23^{\circ} \mathrm{C}$} & 599.91 & 2.60 & 0.17 & 699.70 & 0.20 & 0.01 & 921.87 & 0.36 & 0.01 & 1304.42 & 1.09 & 0.04 & 6.405 \\
\hline & 626.48 & 2.56 & 0.19 & 704.38 & 0.21 & 0.01 & 937.13 & 0.31 & 0.01 & 1311.06 & 1.09 & 0.04 & 6.493 \\
\hline & 612.80 & 2.74 & 0.21 & 700.55 & 0.20 & 0.00 & 924.09 & 0.38 & 0.00 & 1293.14 & 1.18 & 0.03 & 6.400 \\
\hline $\begin{array}{l}\text { Maximum } \\
\text { relative } \\
\text { deviation }\end{array}$ & $8.07 \%$ & $\begin{array}{l}7.03 \\
\%\end{array}$ & $\begin{array}{l}23.5 \\
3 \%\end{array}$ & $3.01 \%$ & $\begin{array}{l}23.5 \\
3 \%\end{array}$ & --- & $4.56 \%$ & $\begin{array}{l}32.2 \\
6 \%\end{array}$ & --- & $2.94 \%$ & $\begin{array}{l}19.1 \\
9 \%\end{array}$ & $\begin{array}{l}33.3 \\
3 \%\end{array}$ & \\
\hline
\end{tabular}

It can be seen from table 3 that compared with the medium speed phase, high speed and extra-high speed phases, the emissions of $\mathrm{CO}_{2}, \mathrm{CO}$ and $\mathrm{THC}$ in the first phase are significantly different. For example, the maximum relative deviation of $\mathrm{CO}_{2}$ which has the largest overall emissions in the first stage is about $8 \%$, while the maximum relative deviation in the last three phases is less than 5\%. It can also be seen from table 3 that CO and THC have a large amount of generation in the low speed phase, but the overall emissions are compared Low. As a result, although the relative deviation of $\mathrm{CO}$ and THC emissions in the later three phases is large,the impact on fuel consumption is small ${ }^{[6-11,15]}$.

In addition, when the vehicle runs to the end of the low-speed phase and enters the middle speed phase, because the vehicle has been running for about ten minutes, the engine oil temperature and coolant temperature gradually rise and tend to be similar under different testing cycle. At this time, even if the immersion temperature conditions are different, the vehicle engine operation status is still similar, so that after entering the middle speed section, the vehicle emissions and fuel consumption levels are not significantly different. Therefore, when studying the effects of immersion temperature $\left(23{ }^{\circ} \mathrm{C}\right.$ and $\left.26{ }^{\circ} \mathrm{C}\right)$ on fuel consumption of the vehicle in WLTC test cycle, this study focuses on the vehicle's exhaust emission and fuel consumption in low speed phase where two immersion temperatures was adopted in WLTC test cycle ${ }^{[12-13]}$.

\subsection{Impact of Immersion Temperature on $\mathrm{CO}_{2}$ Emissions}

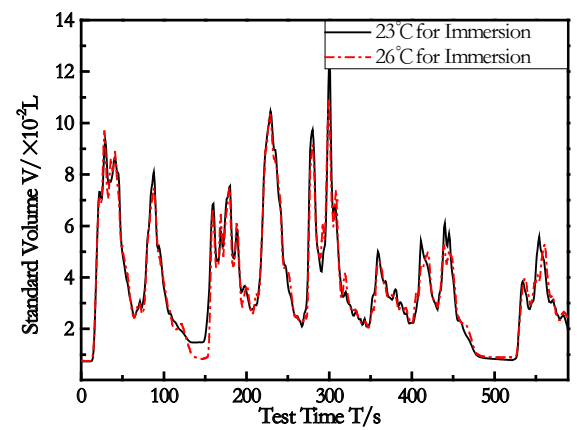

Fig. 2. Effect of different soak temperatures on $\mathrm{CO}_{2}$ emissions of low speed vehicles in wltc test cycle. 
In general, a large amount of $\mathrm{CO}_{2}$ is continuously generated in the whole process of low-speed stage. When the soak temperature is $23{ }^{\circ} \mathrm{C}$ and $26{ }^{\circ} \mathrm{C}$, the volume of $\mathrm{CO}_{2}$ under the standard state is $0.01-0.13 \mathrm{~L}$ and $0.01-0.11 \mathrm{~L}$ respectively, that is to say, the volume of $\mathrm{CO}_{2}$ measured under the condition of high soak temperature is generally smaller than that measured under the condition of low soak temperature. According to the fuel consumption per hundred kilometers of the vehicle to be tested under different immersion temperature conditions in Table 3, it can be found that the fuel consumption of the vehicle in the low speed section is $0.082-0.246 \mathrm{~L} / 100 \mathrm{~km}$ lower than that in the low immersion temperature $\left(23{ }^{\circ} \mathrm{C}\right)$ when adopting the higher immersion temperature $\left(26{ }^{\circ} \mathrm{C}\right)$. The reason for the above phenomenon is that wltc condition is transient condition. Under different soak temperature conditions, with the rapid increase and decrease of vehicle speed, the fuel supply of engine will increase or decrease, resulting in the rapid increase or decrease of $\mathrm{CO}_{2}$ volume generated by combustion, and the corresponding peak and valley values will be generated with the change of time. It can be seen from Figure 2 that although different soak temperatures are used, when the volume of $\mathrm{CO}_{2}$ changes with the vehicle speed, the generation rate of $\mathrm{CO}_{2}$ has little difference. When the lower soak temperature $\left(23{ }^{\circ} \mathrm{C}\right)$ is used, the peak volume of $\mathrm{CO}_{2}$ will be slightly higher than the higher soak temperature $\left(26{ }^{\circ} \mathrm{C}\right)$, making the cumulative emission of $\mathrm{CO}_{2}$ in the whole low-speed section larger. When the immersion temperature is high, after 12 hours immersion, the temperature of the coolant, oil and fuel of the vehicle to be tested is at a high level. When the engine is cold started, because the fuel temperature of the vehicle is high, the gasoline injected into the cylinder is atomized well, mixed with the air more fully, and its combustion and heat release are more sufficient, so the fuel quantity required for the engine to work at the same time is less, and the generated $\mathrm{CO}_{2}$ is less The quantity is also relatively small.

\subsection{Influence of immersion temperature on $\mathrm{CO}$ and THC}

Fig. 3 and Fig. 4 show the average volume of $\mathrm{CO}$ and THC in the exhaust pollutants of vehicles in the low-speed phase with the immersion temperature of $23{ }^{\circ} \mathrm{C}$ and $26{ }^{\circ} \mathrm{C}$ changing with the increase of test time.

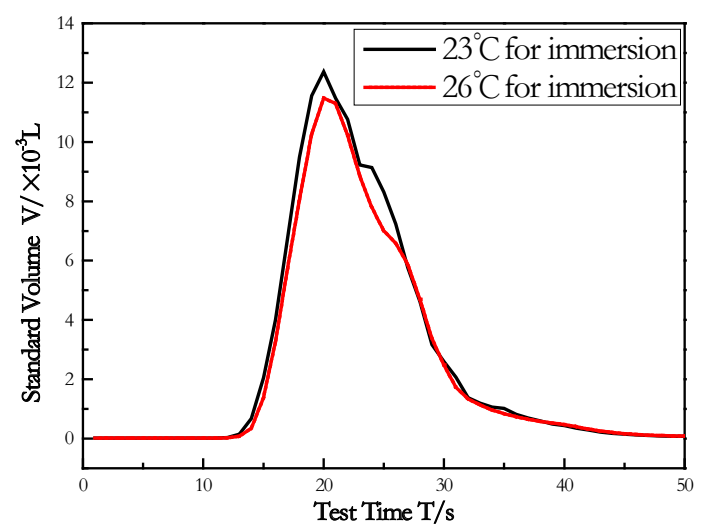

Fig. 3. Effect of different immersion temperature on vehicle's $\mathrm{CO}$ emission of low speed phase in WLTC test cycle. 


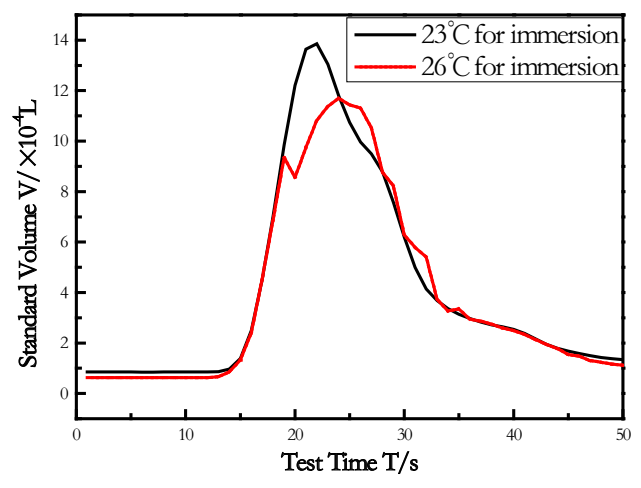

Fig. 4. Effect of different immersion temperature on vehicle's $\mathrm{CO}_{2}$ emission of low speed phase in WLTC test cycle.

It can be seen from Fig. 3 and Fig. 4 that different from the change of vehicle $\mathrm{CO}_{2}$ emission, with the change of vehicle speed, the generation of $\mathrm{CO}$ and THC emitted by the vehicle in the whole low-speed section presents a single peak distribution with the peak value of $1.24 \times 10^{-2} \mathrm{~L}$ and $1.39 \times 10^{-3} \mathrm{~L}$ respectively, and the measured peak emissions appear about 20s after the start of the test as well as the cold start of the vehicle. The reason for the above phenomenon is that the temperature in the cylinder is relatively low when the vehicle is started after 24 hours soaking in the immersion environment specified by the regulations. besides, the temperature of the catalyst has not reached the ignition temperature. At this time, the catalyst conversion efficiency is low. Because the fuel injected into the engine cylinder is in a low temperature environment, it has a poor atomization level. And liquefies after contacting with the cooler cylinder wall which causes fuel's insufficient combustion, resulting in generating a large number of CO and THC in the exhaust gas ${ }^{[4]}$. After several cycles of operation, with the temperature in the engine cylinder increases the fuel atomization quality improved, besides the temperature of the catalyst also reaches the ignition temperature, which significantly reduces the emissions of $\mathrm{CO}$ and THC. Therefore, the emission of tested $\mathrm{CO}$ and $\mathrm{THC}$ of the vehicle show a single peak distribution in the low speed phase. Compared with the lower immersion temperature $\left(23{ }^{\circ} \mathrm{C}\right)$ adapting the higher immersion temperature $\left(26{ }^{\circ} \mathrm{C}\right)$ is more conducive for the mixture and atomization of the fuel, which will benefit the diffusion of the combustion flame in the meantime, resulting in a higher sufficient combustible and a better emission of $\mathrm{CO}$ and the is less, All the phenomenon discovered above is consistent with the findings of Piotr ${ }^{[5]}$.

\subsection{Effect of immersion iemperature on fuel consumption}

The fuel consumption of the vehicle is mainly determined by the $\mathrm{CO}_{2}, \mathrm{CO}$ and THC emission (for example, formula (1)). The average fuel consumption of the vehicle with higher immersion temperature $\left(26{ }^{\circ} \mathrm{C}\right)$ is $0.142 \mathrm{~L} / 100 \mathrm{~km}$ less than that with lower simmersion temperature $\left(23{ }^{\circ} \mathrm{C}\right)$, and the emissions of the three pollutants are relatively low in the low speed phase of WLTC test cycle during the cold start of the vehicle. This is because once the vehicle is cold started, in order to get rich combustible gas the engine will have more fuel injected into cylinder. The lower the temperature is, the worse the atomization of the combustible mixture will be, and less the heat of combustion will be released. So more fuel needs to be provided to ensure the running state of the vehicle. Therefore, the fuel consumption in the cold start stage with higher immersion temperature $\left(26{ }^{\circ} \mathrm{C}\right)$ is higher than that with lower immersion temperature $\left(23{ }^{\circ} \mathrm{C}\right)$. 


\section{Conclusion}

(1)In the WLTC test cycle, the fuel consumption difference of the tested vehicle is mainly reflected in the low speed phase;

(2)Different from the $\mathrm{CO}_{2}$ emission, the $\mathrm{CO}$ and THC production in the low speed phase of WLTC test cycle presents a single peak distribution which is mainly produced by engine's cold start at low temperature;

(3)The tested emissions of $\mathrm{CO}_{2}, \mathrm{CO}$ and THC with a higher immersion temperature $\left(26{ }^{\circ} \mathrm{C}\right)$ at low speed phase of WLTC are lower than those with a low immersion temperature $\left(23^{\circ} \mathrm{C}\right)$;

(4)The fuel consumption of WLTC test cycle at higher immersion temperature $\left(26{ }^{\circ} \mathrm{C}\right)$ is lower than that at lower immersion temperature $\left(23{ }^{\circ} \mathrm{C}\right)$.

This work was financially supported by the Construction of Public Service Platform for Vehicle Emission/Energy Consumption Information System(Improvement of public service capacity of Industrial Technology Foundation 2018), the Integrated Technology of Particulate Matter Capture and Clean Emission for Gasoline Vehicles Projects (No.: 2017YFC0211004 and 2017YFC0211005).

\section{References}

1. General Administration of Quality Supervision, Inspection and Quarantine of the People's Republic of China, China National Standardization Administration.Measurement methods of fuel consumption for light-duty vehicle: GB/T 19233-2008[S]. Beijing: Standards Press of China, 2008.

2. China National Standardization Administration.Fuel consumption limits for passenger cars: GB 19578-2004[S]. Beijing: Standards Press of China, 2004.

3. Ministry of Environmental Protection of the People's Republic of China.Limits and measurement methods for emissions from light-duty vehicles (Phase 6 in China): GB 18352.6 - 2016[S]. Beijing: China Environmental Press, 2016.

4. Yang Yi.Study on Emission Characteristics of Light-duty Vehicle in the Cold-start Stage[J].Technology Innovation and Application,2017(30):176-177.

5. Bielaczyc P, Woodburn J, Szczotka A. A Comparison of Carbon Dioxide Exhaust Emissions and Fuel Consumption for Vehicles Tested over the NEDC, FTP-75 and WLTC Chassis Dynamometer Test Cycles[J]. SAE Technical Papers,2015.

6. Chen Xinyue. Study on the Method of Reducing the Emission of Pollutants in the Cold-start Stage of Light-duty Gasoline Vehicle[D].Jilin Agricultural University,2018.

7. Geng Yangtao. Impact of Driving Style and Cold Start on Emission of Light-duty Vehicles Measured by A Portable Emission Measurement System(PEMS)[D].Chongqing University,2018.

8. Guo Hongsong, Yan yan, Gao Mingqiu, Liu Le, Li Jingyuan, Cao Lei.A Study on the Influence of Test Cycles on the Low-temperature Emissions of China-V Light-duty Gasoline Vehicles[J]. Automotive Engineering, 2018,40(01):14-18+56.

9. Zhao Luming, Liu Wenliang, Wang Meng, Yang Weicai, Wen Xujun, Huang Chenglin. Study on Emission Characteristics of Light-duty Vehicle in the Cold-start Stage Under Normal and LowTemperature[J]. Beijing Automotive Engineering, 2017(06):1-4.

10. Yin Jianli, Qin Zhenhua, Liu Junfei. Study on National V Emission Characteristics of Light Vehicles[J]. Automobile\&Parts, 2017(20):70-71. 
11. Zhang Fan, Yang Zhengjun, Zhong Xianglin. Chassis Dynamometer Tests of Particle Mass [J]. Automotive Safety and Energy, 2017,8(02):190-197.

12. Wu Jianhua, Cheng Liang, Zhu Benyu. Study on Fuel Consumption Characteristics of Light-duty Vehicle[J].Beijing Auto, 2017(05):24-32.

13. Zhang Pengyu, Zhang Xinyu, Hao Lijun, Wang Xuesong. Analysis of Pollutant Emission Characteristics for Light-duty Vehicles under Different Test Cycles, 2016(04):47-49+53.

14. Wen Yi, Ji Liang, Liu Xian, Yang Zhengjun.A Study on Emission Characteristics in China 5 and China 6 Driving Cycles for Light-duty Vehicle[J]. Environmental Science \& Technology, 2016,39(S2):44-48.

15. Ding Jialie, Zhang Tiechen, Gao Junhua, Yang Zhengjun. Research on NMOG Emissions Characteristics of Light-duty Gasoline Vehicles under Different Work Conditions, 2018,16(02):30-36+41.

16. Zheng Tianlei. Comparative analysis of world light vehicle fuel consumption and greenhouse gas emission regulations (I)[J]. Energy Conservation \& Environmental Protection,2010(08):14-17. 